\section{Agricultura familiar e as relações sociais de trabalho: um estudo sobre a pluriatividade na Vila Freire - Cerrito - RS}

Resumo: Este artigo tem como objetivo geral analisar as relações entre a emergência da pluriatividade e as transformações na organização sócioprodutiva da agricultura familiar. Inicialmente, é apresentada uma breve contextualização sobre a agricultura familiar brasileira, as mudanças ocorridas nas relações sociais de trabalho no campo e, especificamente, trata do tema da pluriatividade em um estudo de caso na Vila Freire, município de Cerrito/RS. Nesse sentido, identificou-se que os agricultores combinam atividades agrícolas e não-agrícolas. E assim, ressalta-se que a diversidade de formas de alocação da mão de obra converge para a ampliação das possibilidades e estratégias de reprodução social e permanência das famílias no espaço rural.

\section{Family agriculture and social relations at work: a study about pluriactivity in Vila Freire - Cerrito - RS}

\footnotetext{
Abstract: This paper aims at analyzing the relations between the emergence of pluriactivity and the transformations in the socio-productive organization of family agriculture. First, I will present a brief background on Brazilian family agriculture, the changes occurred in social work relations in the field, and then I will more specifically address the topic of pluriactivity in a case study in Vila Freire, in the city of Cerrito/RS. Accordingly, we found that farmers combine agriculture activity and non agricultural. Thus, it is worth emphasizing that the diversity of forms used to allocate labor converges to the expansion of possibilities and social reproduction strategies and retention of families in rural areas.
}

Cintia Helenice Loper Aires*

Giancarla Salamoni**

* Especialista em Geografia Universidade Federal de Pelotas

** Professora Doutora do departamento de Geografia da Universidade Federal de Pelotas

Palavras-chave:

Agricultura Familiar;

Pluriatividade; Relações

Sociais de trabalho.

Key-Words: Family farming; pluriactivity; Social Relations at Work 


\section{Introdução}

Os processos de colonização e ocupação do país resultaram que grandes porções do território brasileiro fossem distribuídas entre poucos privilegiados, por meio da doação de terras. Esse caráter concentrador propiciou o desenvolvimento da grande lavoura monocultora e mercantil, entretanto, essa forma de organização do espaço agrário esteve desde o inicio associada à agricultura de subsistência, onde os gêneros produzidos eram destinados a abastecer as famílias produtoras e os trabalhadores das grandes fazendas. Segundo Lamarche (1993, p.179), "A agricultura familiar foi profundamente marcada pelas origens coloniais da economia e da sociedade brasileira, com suas três grandes características: a grande propriedade, as monoculturas de exploração e a escravatura".

A grande lavoura, tanto nos tempos coloniais quanto atualmente, é reconhecida por ocupar extensas áreas com um único cultivo e se diferencia da agricultura familiar em vários aspectos. As monoculturas ocupam grandes áreas cultivadas, enquanto a agricultura familiar assenta-se sobre pequenas extensões de terras, produzindo gêneros destinados ao auto-consumo e, os excedentes são destinados a venda externa à propriedade. Ainda, na agricultura familiar encontra-se associada a produção especializada para o mercado e a produção para o consumo familiar.

Nesse sentido, Bonini reafirma a importância da agricultura familiar no contexto atual:

Embora a agricultura patronal de caráter empresarial ocupe uma posição considerável no contexto do agro brasileiro, a agricultura familiar jamais será extinta, uma vez que é a principal responsável pela produção de diferentes gêneros alimentícios que abastecem os grandes centros urbanos. (BONINI, 2004, p.37)

O agricultor familiar também pode ser considerado aquele que possui na agricultura a sua principal fonte de renda e a gestão da propriedade é de responsabilidade da família, bem como a mão-de-obra utilizada , sendo que se for necessário a força de trabalho de terceiros, essa será utilizada de forma complementar. Para Wanderley (2001, p.23) a "agricultura familiar, entendida como aquela em que família, ao mesmo tempo em que é proprietária dos meios de produção assume 0 trabalho no estabelecimento produtivo (...)".

A FAO e o INCRA (1996) definem a agricultura familiar a partir de quatro aspectos principais, a saber:
a) a direção dos trabalhos é exercida pelo produtor;
b) não foram realizadas despesas com serviço de empreitada;
c) sem empregados permanentes e com número médio de empregados temporários me- nor ou igual a quatro ou com um empregado permanente e número médio de empregados temporários menor ou igual a três;
d) com área total menor ou igual a quinhentos hectares para as regiões Sudeste e Sul e mil hectares para as demais regiões. (FAO/ INCRA apud BLUM, 2001, p. 63)

Mais recentemente, o processo de modernização constitui-se em um dos elementos que determinam profundas mudanças no segmento da produção familiar. Gazolla (2006) afirma que as transformações sociais, econômicas e técnicas que ocorreram no meio rural mudaram a vida e as estratégias de reprodução social dos agricultores familiares.

Geografia Ensino \& Pesquisa, v. 17, n.1 p. 41 - 54, jan./abr. 2013

Agricultura familiar e as relações sociais de trabalho: um estudo sobre a pluriatividade na Vila Freire - Cerrito - RS
Estas transformações mudaram principalmente os modos de vivência dos agricultores e as suas estratégias de reprodução social. A agricultura familiar que se assentava, antes deste período, na diversificação produtiva, hoje se reproduz com base no mercado de fatores de produção, na especialização produtiva, nos cultivos voltados ao mercado e com uma intensa diferenciação sócioprodutiva entre as suas unidades. (GAZOLLA, 2006, p. 100)

Após a Segunda Guerra Mundial, com o processo de globalização dos mercados, as economias mundiais se encontram interligadas e as produções, tanto das indústrias quanto da agricultura, 
passam a depender das necessidades do mercado consumidor. Com a dependência dos mercados e com a concorrência de países desenvolvidos, nos quais a agricultura está amparada por políticas públicas e por subsídios, os países subdesenvolvidos vêem-se diante de desafios para fortalecer 0 segmento da produção familiar.

Uma alternativa para muitos agricultores é a aquisição de novas tecnologias agrícolas, porém, muitas vezes essa possibilidade se torna inviável devido à extensão física da propriedade. Para as pequenas propriedades o investimento em maquinários acaba por não responder as expectativas necessárias, devido ao custo de manutenção dos equipamentos contrapondo-se aos benefícios referentes à sua aquisição.

Dessa forma, o produtor familiar que não tem condições de adotar os padrões de tecnologias exigidos pelo mercado encontra dificuldades na comercialização da produção. As atividades agrícolas exigem tempo e energia dos agricultores, principalmente, se forem realizadas com práticas tradicionais, combinando a força manual com a tração animal. Aqueles agricultores descapitalizados não possuem condições para investir na modernização dos equipamentos, necessários para aumentar a sua produção e tornar seu trabalho menos penoso.

Muitos agricultores familiares acabam contratando mão-de-obra externa à propriedade para poder executar todas as tarefas relacionadas a produção, sendo que, o custo da produção se torna elevado e a rentabilidade menor. Assim, muitas vezes, este processo de contratação de mão-de-obra externa à propriedade torna-se inviável para muitos dos agricultores, principalmente, àqueles ligados ao sistema de produção tradicional.

Entre os fatores que podem levar a contratação de mão-de-obra externa à propriedade estão os relacionados ao êxodo rural de alguns dos componentes do grupo familiar. Esse êxodo pode ocorrer por vários motivos como a formação de novas famílias, por doenças, por falta de oportunidade no meio rural, entre outros.

Esses fatores são muitas vezes determinantes para que as famílias de agricultores procurem novas estratégias para continuar se reproduzindo socialmente e residindo no meio rural. Nesse contexto de fragilidade dos agricultores familiares, uma das alternativas para garantir a estabilidade da família é a procura por parte de algum membro da família por ocupação fora da propriedade.

\section{O contexto da agricultura familiar e as relações com a pluriatividade}

A agricultura familiar no Brasil ganhou importância, em termos de políticas públicas específicas para este segmento, a partir da década de 90 . Essa conquista, juntamente com um relativo contexto de crise na agricultura patronal ligada às grandes propriedades e às lavouras empresariais de exportação, teve um papel importante para o fortalecimento da agricultura familiar que é responsável pelo abastecimento do mercado interno de alimentos. A crise no campo ligada á precariedade do modo de vida dos agricultores familiares resultou em vários movimentos que aceleraram a implementação de políticas agrícolas, entre estas a criação do PRONAF - Programa Nacional de Fortalecimento da Agricultura Familiar. Essa política pública foi destinada a auxiliar os agricultores familiares diretamente na produção e para que eles possam se manter no campo, por meio de crédito a juros subsidiados.

O objetivo principal do PRONAF era criar condições para aumento da capacidade produtiva, gerar novos empregos e melhorar a renda das famílias, propiciando uma melhoria na qualidade de vida dos agricultores familiares. Segundo Hespanhol e Costa (2001),

Essa linha de atuação do PRONAF constitui-se numa linha de financiamento do governo federal, com recursos não reembolsáveis, em parceria com os governos municipais, objetivando a implementação, ampliação, racionalização, modernização ou realocação da infra-estrutura pública e de serviços de apoio ao desenvolvimento da agricultura familiar. (HESPANHOL E COSTA, 2001).

Geografia Ensino \& Pesquisa, v. 17, n.1 p. 41 - 54 , jan./abr. 2013

Aires, C. H. L.; Salamoni, G. 
A partir das medidas adotadas pelo Estado para promover a agricultura familiar, gerando empregos e condições mais dignas para os agricultores, a agricultura familiar passou a ter mais destaque no processo de desenvolvimento do país. Porém, este desenvolvimento não atingiu todos os agricultores, mantendo-se em alguns lugares as precárias condições de vida e de reprodução social das famílias rurais.

Para o Ministério do Desenvolvimento Agrário (MDA), que estabelece as diretrizes para a formulação da Política Nacional da Agricultura Familiar e Empreendimentos Familiares Rurais, a lei $\mathrm{n}^{0}$ 11.326, de 24 de Julho de 2006 considera como agricultor familiar e empreendedor familiar rural aquele que pratica atividades no meio rural, atendendo aos seguintes requisitos:

\footnotetext{
I - não detenha área maior do que 4 (quatro) módulos fiscais;

II - utilize predominantemente mão-de-obra da própria família;

III - tenha renda familiar predominantemente originada do próprio estabelecimento ou empreendimento;

IV - dirija seu estabelecimento ou empreendimento com sua família. (MDA, 2008)
}

A agricultura familiar no Rio Grande do Sul passou por um período de transformações sociais, econômicas e produtivas, que ocorreu a partir dos anos 70. 0 agricultor familiar deixa de se assentar na diversificação produtiva e passa se reproduzir com base nos mercados urbanos - industriais, seguindo para a especialização produtiva e para modernização agrícola (máquinas, implementos e insumos químicos).

A modernização a partir da adoção de insumos industriais mudou a realidade social e econômica dos agricultores; com a evolução da tecnologia ocorreu a diminuição da demanda por mão-de-obra nas unidades agrícolas familiares. Desta forma, o processo de modernização se torna um elemento que influencia o êxodo rural. Com a falta de empregos no meio rural percebe-se que ocorre o envelhecimento desta população, sendo que os jovens se deslocam para os centros urbanos em busca de melhores oportunidades de emprego.

Essa realidade foi influenciada e alterada por um elemento que passou a ter relevância para manter as famílias nas propriedades, oportunizando novas possibilidades de ocupação de mão-de-obra. A pluriatividade aparece como elemento dinamizador do espaço rural, ela possibilita que integrantes da família de agricultores possam conciliar atividades agrícolas com atividades não- agrícolas. As atividades não-agrícolas são originadas pelas novas empresas que estão se instalando no meio rural e pelas atividades de mão-de-obra que não estão ligadas a agricultura, como o trabalho doméstico, o comércio e o turismo local.

De acordo com o IBGE, em 2004, a população total do Rio Grande do Sul era de 10.700 .990 habitantes, sendo que 8.648.020 viviam na zona urbana e, 2.052.960 na zona rural. Sendo que a PEA - População economicamente ativa rural ocupada era de 1.178 .340 pessoas e destas 873,40 mil estavam envolvidos em atividades agrícolas e 304,94 mil em atividades não-agrícolas (SCHNEIDER, 2006). E, de acordo com Pesquisa Nacional por Amostra de Domicílios (PNAD, 2008), o valor do rendimento médio mensal (em $\mathrm{R} \$$ ) conforme o tipo de atividade mostra que os rendimentos da ocupação de mão-de-obra não agrícola superam os rendimentos da ocupação agrícola.

Geografia Ensino \& Pesquisa, v. 17, n.1 p. 41 - 54 , jan./abr. 2013

Agricultura familiar e as relações sociais de trabalho: um estudo sobre a pluriatividade na Vila Freire - Cerrito - RS
Noutras palavras, a renda dos domicílios rurais engloba, além dos rendimentos da ocupação agrícola, rendimentos da ocupação não agrícola, que, mesmo nas áreas rurais, é mais bem remunerada que a primeira. A diferença torna-se mais patente se comparados os ganhos decorrentes de trabalho agrícola e não agrícola, considerando apenas os domicílios da área rural: nesse universo, o rendimento médio do trabalho é de $\mathrm{R} \$ 266$, para as ocupações agrícolas, e de $\mathrm{R} \$ 571$, para as não-agrícolas. (PNAD, 2008, p.11)

A renda média mensal da População Economicamente Ativa (PEA) rural, por região, mostra uma disparidade, onde a região Nordeste apresenta uma renda mensal de $R \$ 296,00$ em relação ao Sul do país que apresenta a maior média mensal de renda, correspondente a $R \$ 633,00$. Essa desigualdade de renda também se acentua quando analisamos os rendimentos médios entre gêne- 
ros, nas regiões do Sul e Centro-Oeste a remuneração média recebida por mulheres não chega a $50 \%$ da dos homens. (PNAD, 2008)

Mesmo com as adversidades encontradas no meio rural, as ocupações não agrícolas cresceram, conforme aponta a PNAD:

\begin{abstract}
A PNAD 2008 confirma a tendência de expansão do número de ocupados em atividades não agrícolas no meio rural. Entre 2004 e 2008, as ocupações não agrícolas cresceram, embora o seu peso no total das ocupações tenha sido influenciado também pela queda da PEA rural ocupada. Em contrapartida, as ocupações agrícolas seguem em queda tanto em números absolutos quanto relativos entre 2004 e 2008. Estas tendências reforçam as teses que apontam para a modificação paulatina do meio rural brasileiro, cujo dinamismo vem alterando o perfil e a distribuição das ocupações, reduzindo a dependência das famílias em relação aos rendimentos agrícolas. (PNAD, 2008, p.15)
\end{abstract}

As novas oportunidades de trabalho explicam a tendência do aumento da população rural ou o retorno de pessoas que haviam abandonado o mesmo. A tendência do crescimento da população domiciliada e ligada a pluriatividade no meio rural é confirmada por Schneider (2006):

\begin{abstract}
Nesse sentido, as mudanças relacionadas a PEA rural indicam que o espaço rural gaúcho revela uma nova função para além da tradicional atribuição de local de produção primária. Em 2004, uma parcela não-desprezível da população rural, algo como 15\% (304.940 pessoas) do total, habitava no meio rural, mas estava ocupada em atividades não - ligadas ao setor agropecuário o que, por si só, leva a pensar sobre as formas de trabalho e ocupação deste contingente. E o que é mais relevante: há uma nítida tendência de crescimento as pessoas domiciliadas no meio rural entre os ocupados em atividades não-agrícolas, que em 1992 eram 297 mil e em 2004 chegaram a 304 mil habitantes. (SCHNEIDER, 2006, p. 143)
\end{abstract}

Em regra, fazem parte da mão-de-obra familiar à figura do pai, a mãe e os filhos. Em alguns casos, há a presença de agregados com ou sem ligação de parentesco, que vivem na propriedade e participam do processo produtivo. Cabe destacar, que a mulher possui significativa importância, uma vez que ela atua nos afazeres domésticos e participa do processo produtivo. As mulheres combinam as atividades agrícolas, o cuidado com as crianças e o trabalho doméstico. A respeito do assunto destaca Bonini (2004),

Na família camponesa, as crianças e os mais velhos não participam das atividades mais pesadas, somente aqueles que exigem um menor grau de esforço físico. Cabendo, assim, aos homens executarem as tarefas mais pesadas, como o trabalho na lavoura e o gerenciamento da propriedade. A mulher camponesa exerce múltiplas funções, sendo que as tarefas agrícolas, propriamente ditas, são consideradas apenas como ajuda, ocorrendo desta forma a subestimação do trabalho das mulheres. (BONINI, 2004, p.34)

Apesar de a mulher não ser considerada como mão- de -obra principal na unidade produtiva, e tendo seu trabalho considerado muitas vezes como "ajuda", cabe a ela uma diversidade de afazeres que transformam seu dia numa longa jornada de trabalho. Ela está envolvida em todas as esferas de produção e reprodução da unidade agrícola familiar.

$\mathrm{Na}$ agricultura familiar não ocorre a divisão dos rendimentos obtidos com a produção e comercialização dos produtos. Os recursos que são obtidos pelo resultado do trabalho familiar são novamente empregados na propriedade, na adoção de novas tecnologias agrícolas (maquinários, insumos químicos, sementes e mudas, entre outros), na aquisição de bens de uso doméstico e ainda, na compra de terras.

O desenvolvimento do capitalismo no campo caracteriza-se pelo incremento das relações mercantis, fazendo com que os produtores diminuam a diversificação da produção agrícola. Desta forma, a consequência é a redução da força de trabalho. $E$, muitas vezes, cabe às mulheres buscar fora da propriedade, quando necessário, renda externa para complementar a renda da família,

Geografia Ensino \& Pesquisa, v. 17, n.1 p. 41 - 54, jan./abr. 2013

Aires, C. H. L.; Salamoni, G.

ISSN 2236-4994 
criando um novo modelo de trabalho que irá introduzir mudanças tanto na sua rotina de trabalho quanto para o grupo familiar, que passa a ter uma nova fonte de renda e uma nova classificação, tornam-se uma família pluriativa.

Para Brumer (1996), os principais fatores que afetam a inserção das mulheres rurais em atividades produtivas são: a relação entre o tipo de produção desenvolvida, a tecnologia utilizada, a forma de inserção no mercado dos produtores e a divisão de trabalho que se forma no interior dos estabelecimentos agrícolas.

Quando analisamos o tipo de trabalho assalariado também verificamos que há uma diferenciação entre os gêneros, os homens detêm os empregos agrícolas permanentes, enquanto as mulheres atuam durante o período de grande demanda de serviço. Os empregos variam de acordo com o setor de emprego; para as mulheres ocorre um predomínio de empregos não- agrícolas como: domésticas, cozinheiras, enquanto para os homens há um predomínio de trabalhos agrícolas. Brumer (1996, p.53) complementa dizendo: "Homens e mulheres, bem como, com frequência as crianças, participam deste trabalho, pois somente o trabalho masculino não é suficiente para garantir o sustento da família".

Os jovens aparecem no meio rural como símbolo e expressão de redefinições e questionamentos sobre a ruralidade e a manutenção da agricultura familiar. Eles se movem em busca de realização de seus sonhos e projetos de vida. As evidências sugerem que os jovens estão clamando por mudanças na condição social e nas relações que fundamentam a agricultura familiar. No entanto, quando não encontram espaço para a realização das transformações desejadas, buscam no meio urbano meIhores condições de vida, mas encontram sérias dificuldades para a sua inclusão social e de trabalho.

$\mathrm{Na}$ agricultura familiar, as crianças convivem diariamente com a rotina de trabalho dos pais na propriedade, logo, elas se familiarizam desde cedo com o trabalho e com a sua representação. $O$ trabalho para o agricultor familiar significa a possibilidade de estabilidade e de honrar seus compromissos. Desta forma, os adolescentes, em geral, aprendem logo a diferenciar funções, deveres e a normatizar os princípios de trabalho. Na propriedade rural os adolescentes, a partir dos 15 anos, passam a assumir as tarefas de adultos, passando a ser vistos como tal no espaço social e de lazer. Embora a participação dos jovens no mundo de trabalho na agricultura familiar possua importância singular em cada propriedade, essa participação vai depender de cada família e das condições objetivas e subjetivas que as permeiam. Para Stropasolas (2006),

\footnotetext{
Embora a ausência das crianças no ambiente do trabalho não seja a regra no conjunto das famílias pesquisadas, a freqüência e a intensidade de sua participação oscilam, dependendo do caso considerado, aflorando aqui algumas variações no seio desta categoria social, sendo as condições econômicas e produtivas, a disponibilidade de terra e de mão-de-obra alguns fatores determinantes desta variação. (STROPASOLAS, 2006, p.213)
}

Por outro lado, o caráter seletivo dos processos migratórios relacionados à agricultura familiar no Sul do Brasil apresenta a masculinização do meio rural. Sendo que a Pastoral da Juventude Rural do Rio Grande do Sul apresenta em sua pesquisa que o universo rural compõe-se de $53 \%$ de rapazes e $47 \%$ de moças. Isso significa que por necessidade ou para realização de anseios pessoais as mulheres estão buscando realização fora do meio rural. (STROPASOLAS, 2006)

Assim, o agricultor familiar diante das inovações tecnológicas e evolução dos mercados

Geografia Ensino \& Pesquisa, v. 17, n. 1 p. 41 - 54 , jan./abr. 2013

Agricultura familiar e as relações sociais de trabalho: um estudo sobre a pluriatividade na Vila Freire - Cerrito - RS adaptou-se às novas mudanças para conseguir permanecer na sua propriedade. Desta forma, 0 agricultor passou a assumir novas ou múltiplas atividades, em alguns casos, tornou-se necessário que membros da família buscassem trabalho externo a propriedade para que a família pudesse continuar se mantendo no campo. 


\section{Caracterização sócioprodutiva das unidades familiares na Vila Freire- Cerrito- RS: a emergência da pluriatividade}

O município de Cerrito foi criado em 28 de dezembro de 1995, pela lei nº 10656/95. Até esta data, o município de Cerrito era um dos distritos do município de Pedro Osório.

De acordo com o IBGE - Instituto Brasileiro de Geografia e Estatística de 2010, o município de Cerrito possui uma população de 6.402 habitantes e uma área de unidade territorial que corresponde a $452 \mathrm{Km}^{2}$. As principais vias de acesso à cidade de Cerrito são: as BRs 293 e 116 e a RS 703.

O município de Cerrito é formado por três distritos, sendo o primeiro distrito a sede urbana, 0 segundo denominado Alto Alegre e o terceiro Vila Freire, que terá destaque nesta pesquisa. Cerrito encontra-se na longitude $52,8^{\circ}$ oeste e na latitude de $31,8^{\circ}$ sul e faz limites com os municípios de Capão do Leão, Morro Redondo, Piratini, Canguçu e Pedro Osório.

Segundo dados da FEE - Fundação de Economia e Estatística, de 2011, o município possui uma densidade demográfica de 14,1 habitantes por $\mathrm{Km}^{2}$. Uma taxa de analfabetismo, em 2010, de pessoas com 15 anos ou mais de 12,8\% e uma expectativa de vida de 71,60 anos.

A economia do município está baseada na produção primária, com destaque para a presença das propriedades familiares, com área até 50 hectares. A maioria dos produtores familiares do município produz alimentos para o autoconsumo e quando ocorre o excedente de produção este é destinado à venda. Nas palavras de Hepp, "A produção excedente é canalizada para o atacadista, ou seja, comerciantes que circulam no meio rural adquirem os produtos e determinam o preço dos mesmos no ato da compra." (HEPP, 2002, p.77)

Esta pesquisa abrangeu dez propriedades de agricultores familiares localizados na Vila Freire, sendo que seis famílias adotam a pluriatividade, ou seja, combinam as atividades agrícolas com as atividades não-agrícolas. Cabe ainda ressaltar, que as propriedades foram classificadas, pela sua dimensão física, como pequenas propriedades. De acordo com Blum (2001), para que seja considerada uma pequena propriedade, a unidade familiar deve possuir no máximo cinquenta hectares. Sendo que até dez hectares é considerado mini- propriedade, e de onze a cinquenta hectares, a propriedade é classificada como pequena. De acordo com essa classificação, na área pesquisada, os agricultores se encontram entre mini proprietários e pequenos proprietários de terras, visto que, o tamanho das propriedades do grupo de agricultores analisado varia de três (3) a trinta e três (33) hectares.

A pequena dimensão física das propriedades, os preços elevados dos insumos e os baixos valores obtidos com a venda da produção, na maioria dos casos, fazem com que somente as atividades agrícolas tornem inviável a manutenção das famílias, devido aos baixos rendimentos obtidos exclusivamente com a agricultura. Esses fatores contribuem para que os agricultores adotem a pluriatividade como uma alternativa para geração de renda.

As famílias dos agricultores, analisados neste trabalho, afirmam que a obtenção de alimentos e de renda, baseados somente nas atividades internas das unidades produtivas, se tornou insuficiente para garantir as necessidades de todos os membros da família. Portanto, as atividades não-agrícolas respondem por importante parcela da renda familiar e para a permanência dos seus membros domiciliados na localidade da Vila Freire.

Entre as dez unidades de produção agrícola familiar, verifica-se que todas as famílias analisadas eram proprietárias, duas das famílias trabalhavam em parceria, em terras de terceiros, e uma família arrendava terras de terceiros para ampliar a área destinada a produção.

Quando os entrevistados foram questionados sobre como eles haviam obtido as suas terras, identificou-se que oito famílias obtiveram parte das suas terras por meio de herança, sendo que cinco delas obteve por herança somando a compra de terceiros, e as outras cinco adquiriram suas terras por herança e ou compra de parentes.

Nas dez unidades produtivas analisadas, apenas em uma não encontramos a criação de bovinos. Nas outras unidades o número de bovinos encontrado varia de 2 até 30 cabeças, sendo

Geografia Ensino \& Pesquisa, v. 17, n.1 p. $41-54$, jan./abr. 2013

Aires, C. H. L.; Salamoni, G.

ISSN 2236-4994 
que 0 total de bovinos encontrados chega a 117 cabeças. Todas as unidades produtivas utilizam 0 rebanho de bovinos para o consumo da própria família e, entre estas, quatro produtores direcionam algumas cabeças para a venda externa. Apenas em duas propriedades encontramos equinos, sendo eles utilizados como tração animal nos trabalhos agrícolas.

Em seis unidades produtivas encontramos a criação de aves, no total de 137 animais, destinados ao consumo interno da propriedade. Em relação aos suínos foram encontrados em seis das unidades analisadas, somando um total de 15 cabeças, todos para o consumo familiar. No que tange aos ovinos, foi encontrado apenas um animal em uma das unidades analisadas, como também apenas um açude em uma das propriedades, sendo que não se soube relatar o número exato de peixes existentes, que são direcionados para o consumo da família e também o açude é visto como uma oportunidade de lazer para a família. (Tabela 1)

Tabela 1- Tipo de rebanho e destino da produção nas unidades produtivas de Vila Freire - Cerrito /RS

Tipo de rebanho e destino da produção nas unidades produtivas

\begin{tabular}{|c|c|c|c|c|}
\hline \multirow[t]{2}{*}{ Tipo de rebanho } & \multirow[t]{2}{*}{$\begin{array}{l}\text { Número total } \\
\text { de cabeças }\end{array}$} & \multicolumn{2}{|c|}{$\begin{array}{l}\text { Número de produtores por destino da } \\
\text { dução }\end{array}$} & pro- \\
\hline & & Consumo & Venda & \\
\hline Bovinos & 117 & 9 & 4 & \\
\hline Eqüinos & 2 & 2 & - & \\
\hline Aves & 137 & 6 & - & \\
\hline Suínos & 15 & 6 & - & \\
\hline Ovinos & 1 & 1 & - & \\
\hline
\end{tabular}

Fonte: Pesquisa de campo, 2008.

Quando analisamos os principais tipos de cultivos encontrados nas unidades produtivas familiares na Vila Freire, percebemos que as batatas doce e inglesa, feijão e o milho possuem uma maior relevância no contexto dos cultivos agrícolas na localidade. Dentre as dez famílias analisadas, apenas quatro delas plantam batata doce e batata inglesa, uma família planta cebola, outra cultiva mandioca e outra família trabalha com o cultivo de fumo, o feijão aparece como cultivo em cinco das unidades agrícolas analisadas e o milho aparece como cultivo na maioria das análises, sendo encontrado em nove das dez unidades. Todos esses cultivos são direcionados para o consumo da família, sendo que somente o milho e a mandioca são usados também para a alimentação dos animais. (Tabela 2)

Tabela 2- Tipos de cultivos por destino de produção em cada unidade produtiva da Vila Freire - Cerrito / RS

Geografia Ensino \& Pesquisa, v. 17, n.1 p. 41 - 54 , jan./abr. 2013

Agricultura familiar e as relações sociais de trabalho: um estudo sobre a pluriatividade na Vila Freire - Cerrito - RS

\begin{tabular}{l|l|l} 
Tipos de cultivos & $\begin{array}{l}\text { Produção por unidade } \\
\text { para consumo familiar }\end{array}$ & $\begin{array}{l}\text { Produção por unidade } \\
\text { para consumo animal }\end{array}$ \\
\hline Batata & 4 & - \\
\hline Batata Doce & 4 & - \\
\hline Cebola & 1 & - \\
\hline Feijão & 5 & - \\
\hline Fumo & 1 & - \\
\hline Mandioca & 1 & 1 \\
\hline Milho & 9 & 9
\end{tabular}

Fonte: Pesquisa de campo, 2008.

A agricultura familiar é caracterizada pela pequena propriedade, pela mão-de-obra predominantemente familiar, onde a própria família é responsável tanto pela gestão da propriedade como pelos meios de produção. A produção familiar é marcada pela associação entre a policultura e a 
pecuária. Essa associação beneficia os agricultores, pois, algumas das suas culturas servem tanto para o consumo familiar quanto para a alimentação dos animais, de onde a maioria retira grande quantidade de produtos de origem animal que complementam a sua alimentação e a sua renda.

Este é o caso dos agricultores de Vila Freire, localidade onde ocorre a conciliação da policultura com a pecuária, sendo uma das principais culturas o milho, que serve tanto para o uso doméstico quanto para a alimentação dos animais. No caso das aves, os produtores se beneficiam com a carne e com os ovos que são usados para o consumo. Os suínos fornecem carne e os bovinos servem tanto como força de trabalho na maioria das propriedades analisadas, bem como, para a produção de carne e leite. No caso do leite, observou-se que algumas famílias, além da produção para consumo, comercializam o excedente para complementar a renda doméstica.

Os principais produtos de origem animal que são produzidos nas propriedades são: o leite que aparece em sete unidades produtivas, os ovos que são encontrados em cinco delas, o mel em duas e a carne que aparece na maioria das unidades; encontra-se a produção de carne em nove unidades agrícolas. Quando questionados nas entrevistas para verificar se esses produtos eram suficientes para o sustento da família, cinco produtores relataram que sim, e cinco responderam que não, que eles precisavam comprar alguns produtos para complementar as necessidades da família. Verificamos, também, se outros produtos eram processados dentro do estabelecimento, encontramos as conservas, o queijo, a banha, o salame e os vinhos. Todos esses produtos são de origem caseira e servem somente para o consumo da família.

Os tipos de força utilizados nos trabalhos das unidades agrícolas são de origem animal e mecânica. A prevalência do tipo de força é a animal, que aparece em oito das propriedades, sendo que cinco delas utiliza somente a força animal, duas dessas somam essa força á força-mecânica, que é alugada nos períodos de safras ou quando há uma demanda maior de serviço, e uma unidade utiliza tanto a força animal como a mecânica (própria). Em relação a força mecânica, ela é utilizada em três propriedades, esses produtores utilizam somente força mecânica própria e, outras duas famílias utilizam a força animal, e quando necessário, alugam a força mecânica para sanar as necessidades de produção.

A mão-de-obra utilizada nas propriedades analisadas são predominantemente de origem familiar, apenas uma das unidades utiliza a mão-de-obra temporária. Essa força de trabalho utilizada corresponde a uma pessoa e ocorre em época de safra, e em torno de trinta dias anuais.

Quando analisamos a composição familiar nas dez unidades pesquisadas, verificamos que em cada unidade encontra-se de dois até no máximo quatro integrantes. Tendo no total nove casais, uma viúva e dez jovens solteiros. Ao analisarmos as classes etárias dos membros das famílias de agricultores percebemos que do zero até os dez anos encontramos quatro pessoas, dos onze até os vinte anos e dos vinte e um até os trinta anos encontramos três pessoas em cada faixa etária, dos trinta e um até os quarenta anos encontramos duas pessoas. E dos quarenta e um até os cinqüenta e dos cinquenta e um até os sessenta encontramos sete pessoas em cada faixa etária, e, a partir dos sessenta anos, encontramos quatro pessoas na área analisada.(Tabela 3)

Tabela 3- Composição do grupo familiar na Vila Freire - Cerrito /RS

\begin{tabular}{l|l} 
Classes Etárias & Número de pessoas \\
\hline $0-10$ & 4 \\
\hline $11-20$ & 3 \\
\hline $21-30$ & 3 \\
\hline $31-40$ & 2 \\
\hline $41-50$ & 7 \\
\hline $51-60$ & 7 \\
\hline 61 e mais & 4
\end{tabular}

Geografia Ensino \& Pesquisa, v. 17, n.1 p. 41 - 54, jan./abr. 2013

Aires, C. H. L.; Salamoni, G.

Fonte: Pesquisa de campo, 2008. 
Podemos perceber que ocorre um aumento no número de pessoas de acordo com o aumento das classes etárias, isso significa que está ocorrendo um envelhecimento da população rural do local, esse fato já vem sendo estudado há alguns anos, em outros locais. Blum (2001) explica que essa tendência ao envelhecimento da população do meio rural é devido às poucas oportunidades de oferta de mão-de-obra no meio rural para os jovens e ao baixo índice de infra-estrutura necessária para o aumento do nível de vida dos moradores. Este fato é relevante para que os jovens procurem nos centros urbanos, novas oportunidades de emprego e melhores condições de vida.

A escolaridade dos agricultores envolvidos na pesquisa mostra que a maioria não concluiu 0 ensino fundamental. Treze pessoas estudaram da $1^{\circ}$ a $4^{\circ}$ série incompleta, uma concluiu até a $4^{\circ}$ série, oito estudaram da $5^{\circ}$ a $8^{\circ}$ série incompleta, quatro possuem o ensino médio incompleto e, duas completaram, apenas uma pessoa possui curso superior e três não se encontram em idade escolar.

A pluriatividade possui algumas características, dentre as fundamentais, encontramos a interação entre a agricultura, a unidade familiar e o mercado de trabalho. Ou seja, para Schneider "A pluriatividade refere-se a um fenômeno que se caracteriza pela combinação das múltiplas inserções ocupacionais das pessoas que pertencem à mesma família. "(SCHNEIDER, 2006, p. 139)

Ao analisarmos as relações sociais de trabalho que predominam na Vila Freire e, o número de pessoas que atuam, de acordo com os tipos de ocupação da mão de obra, percebemos que sete pessoas dedicam-se integralmente as atividades agrícolas no interior da unidade produtiva; seis trabalham fora da propriedade e combinam com ocupações não agrícolas fora da unidade familiar; três trabalham em tempo parcial na unidade produtiva e conciliam este com o trabalho doméstico familiar; sete pessoas dedicam-se somente ao trabalho doméstico; uma estuda e no restante do tempo dedica-se as atividades na unidade produtiva; duas somente estudam e duas ainda não estão em idade escolar (estas últimas são crianças menores).(Tabela 4)

Tabela 4- Tipos de trabalho nas unidades produtivas (UP) e número de pessoas por atividade na Vila Freire - Cerrito/ RS

Geografia Ensino \& Pesquisa, v. 17, n.1 p. 41 - 54, jan./abr. 2013

\begin{tabular}{l|l} 
& \\
Tipos de trabalho nas unidades produtivas & Número de pessoas \\
Tempo Integral na UP & 7 \\
\hline Trabalho fora e dentro da UP & 6 \\
\hline Tempo parcial na UP mais trabalho doméstico & 3 \\
\hline Somente trabalho doméstico na UP & 7 \\
\hline Tempo parcial na UP mais estuda & 1 \\
\hline Somente estuda & 2 \\
\hline Criança sem idade escolar & 2
\end{tabular}

Fonte: Pesquisa de campo, 2008.

Das dez unidades produtivas analisadas seis delas estão ligadas a mão-de-obra não-agrícola e, portanto, tornam-se famílias pluriativas, ou seja, algum membro da família trabalha em alguma atividade que não seja a agrícola. Verificamos que três pessoas estão ocupadas na construção civil; uma em atividades no comércio local; uma trabalha como mão-de-obra em outras propriedades rurais executando serviços diversos; uma em trabalho doméstico e um como servidor público. Uma família para ser pluriativa precisa que alguns membros da família continuem com os trabalhos agrícolas, enquanto outros mantenham laços com outras atividades fora da agricultura. (Tabela 5)

Agricultura familiar e as relações sociais de trabalho: um estudo sobre a pluriatividade na Vila Freire - Cerrito - RS 
Tabela 5- Tipo de atividades agrícolas e não-agricolas fora das propriedades na Vila Freire- Cerrito/RS

\begin{tabular}{l|l} 
Tipo de atividade & Número de pessoas \\
\hline Construção Civil & 3 \\
\hline Comércio Local & 1 \\
\hline Trabalho Agrícola & 1 \\
\hline Trabalho Doméstico & 1 \\
\hline Serviço Público & 1
\end{tabular}

Fonte: Pesquisa de campo, 2008.

Os trabalhos não-agrícolas citados, em que ocorre a inserção de mão-de-obra, estão todos basicamente concentrados na localidade onde residem os pluriativos. De acordo com os relatos, verificamos que o número de dias trabalhados fora das atividades agrícolas varia, sendo de dez a trinta dias mensais. Nas palavras de Schneider (1999),

\begin{abstract}
$\mathrm{O}$ assalariamento constitui-se, neste caso, numa alternativa estratégica às dificuldades enfrentadas pelos colonos. A inadequação do sistema produtivo tradicional, que esgotava o solo e gerava poucos ganhos de produtividade, somada aos problemas de reprodução do modo de vida colonial como um todo. Tornaram os empregos fora da propriedade uma opção com dupla vantagem: obter rendas e ganhos econômicos para garantir a subsistência familiar e ter a possibilidade de permanecer residindo na propriedade agrícola, plantando os produtos alimentares de consumo básico. (SCHNEIDER, 1999, p. 112)
\end{abstract}

Os trabalhos não-agrícolas contribuem para o aumento de oferta de mão-de-obra no meio rural, desta forma, ocorre uma diminuição do êxodo rural, que causa uma saturação dos centros urbanos e o esvaziamento do meio rural e, consequentemente, uma diminuição na oferta de produtos agrícolas. Esta nova forma de mão-de-obra permite novas possibilidades de obtenção de renda para os integrantes das famílias, possibilitando que essas famílias possam ampliar seus rendimentos e manter suas propriedades rurais.

Quando questionadas sobre as razões que levou os membros das famílias a trabalhar em atividades não-agrícolas, a maioria das famílias relatou que a falta de dinheiro para compra de insumos com preços elevados e a área da propriedade, considerada como insuficiente para gerar renda somente com a produção agrícola, foram as principais causas para a procura de novas oportunidades de trabalho fora da propriedade. Percebemos isso, quando as famílias relatam que todos os membros que trabalham fora da propriedade em trabalhos não-agrícolas contribuem para as despesas da família e das unidades produtivas.

A maior parte da renda obtida com as atividades não-agrícolas é investida na propriedade rural. Os principais investimentos realizados no último ano agrícola, nas propriedades com renda dos pluriativos são: aquisição de terras em uma unidade produtiva, aquisição de veículos em três unidades, em uma ocorreu à construção e reforma das benfeitorias na propriedade e em outras três unidades não houve nenhum investimento no último ano agrícola.

Percebemos, também, que com o envelhecimento da população que reside no campo, faz com que outra renda possa se tornar importante para o processo de manutenção das propriedades e para manter as famílias no campo. Referimos - nos a aposentadoria: três das famílias pesquisadas possuem aposentados que contribuem para o processo de manutenção e permanência dos integrantes da família no meio rural.

\section{Considerações Finais}

As combinações da agricultura com atividades que lhe são exteriores é uma conduta bastante antiga, tanto no Brasil, quanto em outras regiões do mundo, mesmo que não reconhecidas
Geografia Ensino \& Pesquisa, v. 17, n.1 p. 41 - 54, jan./abr. 2013

Aires, C. H. L.; Salamoni, G.

ISSN 2236-4994 51 
como típicas de pluriatividade. Ela aparece como uma forma de manter o exercício da agricultura na unidade familiar, ao invés de representar o fim das práticas agrícolas. Assim, nos dias atuais, pode-se dizer que a pluriatividade representa uma das estratégias de reprodução social da agricultura familiar, valendo-se de fatores internos e externos da unidade produtiva para tal objetivo.

A produção familiar passou por muitas transformações nos últimos anos e hoje é considerada um importante segmento na produção e diversificação de gêneros agrícolas destinados à alimentação no Brasil. Porém, as condições de vida dos agricultores familiares, muitas vezes continua precária e, para amenizar essas dificuldades, os agricultores adotam novas alternativas para empregar a mão de obra do grupo doméstico. Assim, a pluriatividade se tornou uma importante forma de geração de renda para manter as famílias no meio rural.

A agricultura familiar na área pesquisada é caracterizada pela pequena propriedade, pela mão-de-obra predominantemente familiar, onde a própria família é responsável tanto pela gestão da propriedade como pelos meios de produção. A produção familiar é marcada pela associação entre a policultura e a pecuária.

Normalmente, quando ocorre um desequilíbrio entre oferta de mão-de-obra e a disponibilidade de trabalho em uma propriedade é comum que parte da família busque outras atividades para suprir suas necessidades. Nesse sentido, as atividades não agrícolas cada vez mais estão tendo importância e relevância no contexto da agricultura familiar da Vila Freire.

Ao analisarmos as relações sociais de trabalho que predominam na área pesquisada, percebe-se que existem tanto pessoas que se dedicam integralmente as atividades agrícolas no interior da unidade produtiva, quanto algumas que trabalham fora da propriedade, combinando ocupações agrícolas e não-agrícolas.

Percebe-se, então, que os membros que trabalham fora da propriedade, em trabalhos agrícolas e não-agrícolas, contribuem com rendimentos para as despesas da família e das unidades produtivas. Pois, a maior parte da renda obtida com as atividades não-agrícolas é investida na propriedade rural, como para aquisição de terras, aquisição de veículos, construção e reforma de benfeitorias, entre outras.

\section{Referências Bibliográficas}

ALENTEJANO, Paulo Roberto R. Pluriatividade: uma noção válida para a análise da realidade agrária brasileira. In: TEDESCO, João Carlos. Agricultura Familiar: realidades e perspectivas. $3^{\circ}$ ed. Passo Fundo: Ed. UFP, 2001. p. 149 - 178.

ABRAMOVAY, Ricardo. O Futuro das Regiões Rurais. Porto Alegre: Ed. da UFRGS, 2003.

BONINI, Cristiane Vieira. A importância da mulher na agricultura familiar: o exemplo das trabalhadoras rurais na colônia Osório- Cerrito Alegre - Pelotas RS. 2004, (Monografia de Conclusão de curso), UFPEL, Pelotas.

BLUM Rubens. Agricultura familiar: estudo preliminar da definição, classificação e problemática. In: TEDESCO, João Carlos. Agricultura Familiar: realidades e perspectivas. $3^{\circ} \mathrm{ed}$. Passo Fundo: Ed. UFP, 2001. p. 57 - 106.

Geografia Ensino \& Pesquisa, v. 17, n.1 p. 41 - 54, jan./abr. 2013

Agricultura familiar e as relações sociais de trabalho: um estudo sobre a pluriatividade na Vila Freire - Cerrito - RS
BRUMER, Anita. Qual a vocação produtiva da agricultura familiar? Globalização, produção familiar e trabalho na agricultura. In: TEDESCO, João Carlos. Agricultura Familiar: realidades e perspectivas. $3^{0} \mathrm{ed}$. Passo Fundo: Ed. UFP, 2001. p. 223 - 254.

BRUMER, Anita. Mulher e Desenvolvimento Rural. In: PRESVELOU, C.; ALMEIDA, F.R.; ALMEIDA, A.A.(Orgs.). Mulher, família e desenvolvimento rural. Santa Maria: Ed. da UFSM, 1996. p. $39-58$. 
CALDAS, Pedro. Pedro Osório, Sim Senhor! Retrato de um município gaúcho. Pelotas: Saty, 1990. 124 p.

FEE- Fundação de Economia e Estatística. Dados de 2000, 2009, 2010 e 2011. Disponível em < www.fee.tche.br >. Acesso em 11 de abril de 2012 e 30 de outubro de 2012.

GAZOLLA, M. O processo de mercantilização do consumo de alimentos na agricultura familiar. In: SCHNEIDER, S. (Org.). A diversidade da agricultura familiar. Porto Alegre: Editora da UFRGS, 2006.

HEPP, Vera Enilda Pautz. A imigração alemã e as transformações culturais: 0 exemplo da Colônia Passo do Santana -Cerrito - RS. Pelotas, 2002. Monografia

IBGE- Instituto Brasileiro de Geografia e Estatística. Censo demográfico; 2006; 2007 e 2008. Disponível em:<www.ibge.gov.br>. Acesso em: 11 de abril de 2012.

ILHA NETO, S. F. Da Sociologia rural à Sociologia do território. Revista Ciência e Ambiente, Santa Maria, n. 15, 1997. p. 17- 30.

LAMARCHE, H. A agricultura familiar. Campinas: UNICAMP, 1993. 336 p.

MDA- Ministério de Desenvolvimento agrário: Inserção da agricultura familiar na alimentação escolar. Disponível em: <WWW.mda.gov.br/saf>. Acesso em 11 de abril de 2012.

MONTOYA, Marco Antonio; GUILHOTO, Joaquim J. M. Mudança estrutural no agronegócio brasileiro e suas implicações na agricultura familiar. In: TEDESCO, João Carlos. Agricultura Familiar: realidades e perspectivas. $3^{\circ}$ ed. Passo Fundo: Ed. UFP, 2001. p. 179 - 222.

PNAD 2008. Primeiras análises - o setor rural; 2010. V. 42. Disponível em: <www.ipea. gov.br/>. Acesso em 11 de abril de 2012.

SACCO DOS ANJOS, Flavio. Agricultura Familiar, Pluriatividade e Desenvolvimento Rural no Sul do Brasil. Pelotas: EGUFPEL, 2003. 374 p.

SACCO DOS ANJOS, Flavio. A agricultura familiar em transformação: o caso dos colonos - operários de Massaranduba (SC). Pelotas: Ed.Universitária, 1995. 169 p.

SCHNEIDER, Sérgio. Agricultura familiar e industrialização; pluriatividade e descentralização industrial no Rio Grande do Sul. Porto Alegre: Ed. da UFRGS, 1999.

. A Diversidade da Agricultura Familiar. Porto Alegre: Ed. UFRGS, 2006.

A Pluriatividade na Agricultura Familiar. Porto Alegre: Ed. UFRGS, 2003.

A pluriatividade como estratégia de reprodução social. Revista Estudos Sociedades e Agricultura, nº 16, p. 164 -184, 2001.

STROPASOLAS, Valmir Luiz. O mundo rural no horizonte dos jovens. Florianópolis: Ed. da UFSC, 2006. 346 p.

TEDESCO, João Carlos. Contratualização e racionalidade familiar. In: TEDESCO, João Carlos. Agricultura Familiar: realidades e perspectivas. $3^{\circ} \mathrm{ed}$. Passo Fundo: Ed. UFP, 2001. p. $107-148$.

Geografia Ensino \& Pesquisa, v. 17, n.1 p. 41 - 54 , jan./abr. 2013

Aires, C. H. L.; Salamoni, G. 
TREMEA, Odolir. Uma proposta para viabilizar a agricultura familiar: o pacto Novo Rio Grande. In: TEDESCO, João Carlos. Agricultura Familiar: realidades e perspectivas. $3^{\circ} \mathrm{ed}$. Passo Fundo: Ed. UFP, 2001. p. $395-405$.

WANDERLEY, Maria de Nazaré B. Raízes históricas do campesinato brasileiro. In: TEDESCO, João Carlos. Agricultura Familiar: realidades e perspectivas. $3^{\circ} \mathrm{ed}$. Passo Fundo: Ed. UFP, 2001. p. $21-56$.

\section{Correspondência:}

Cintia Helenice Loper Aires - Passeio Um n 777, Jardim das Tradições Bairro: Três Vendas, Cidade: Pelotas/ RS.

E-mail: cintiaires1@hotmail.com

Recebido em 14 de maio de 2012.

Revisado pelo autor em 25 de outubro de 2012.

Aceito para publicação em 21 de novembro de 2012. 